\title{
A Common Complication After an Ileal Pouch-Anal Anastomosis With a Loop Ileostomy in Patients With Ulcerative Colitis: Small Bowel Obstruction
}

\author{
Chang-Nam Kim \\ Department of Surgery, Eulji University School of Medicine, Daejeon, Korea
}

\section{See Article on Page 94-100}

Ulcerative colitis (UC) is a chronic disease characterized by recurrent inflammation of the colonic mucosa. It affects the rectum and the colon in a continuous fashion [1]. Because UC is well controlled by medical management, medical management is the first choice for treatment. If medical management fails, the patient will require surgery. Indications for elective surgery include complications or side effects of medications, dysplasia, invasive cancer, extraintestinal manifestations, and growth retardation, whereas a toxic megacolon, fulminant colitis, perforation, and continuous severe colorectal bleeding are indications for emergency surgery [2]. One of 2 surgical approaches is recommended: a total proctocolectomy with an end ileostomy and a total proctocolectomy with an ileal pouch-anal anastomosis (IPAA). The total proctocolectomy with a Kock pouch is rarely used these days due to the increased risk of pouch outlet obstruction. The most commonly performed approach is the IPAA, and according to the patient's clinical condition, it is performed in 1,2, or 3 steps [3]. The early postoperative complications of an IPAA are pouch bleeding, pelvic abscess, and anastomotic rupture. The late complications are pouchitis, a pouch-vaginal fistula, a perianal abscess or fistula, and an anastomotic stricture [4].

In a study of the incidence of loop ileostomy-related complications, the most common stoma-related complication was parastomal dermatitis (34.8\%), followed by small bowel obstruction

Correspondence to: Chang-Nam Kim, M.D.

Department of Surgery, Eulji University Hospital, Eulji University School of Medicine, 95 Dunsanseo-ro, Seo-gu, Daejeon 35233, Korea

Tel: +82-42-259-1335, Fax: +82-42-259-1335

E-mail: kimcn7@gmail.com

ORCID code: https://orcid.org/0000-0001-7781-9119

(C) 2018 The Korean Society of Coloproctology

This is an open-access article distributed under the terms of the Creative Commons Attribution NonCommercial License (http://creativecommons.org/licenses/by-nc/4.0) which permits unrestricted noncommercial use, distribution, and reproduction in any medium, provided the original work is properly cited.
(SBO, 22.8\%) [5]. Another study suggested that a postoperative SBO was the most common complication of an IPAA (25.3\%), and of those patients, $27.6 \%$ needed another operation [6]. The incidence of $\mathrm{SBO}$ was significantly higher when the distance from the ileostomy to the ileal pouch was less than $30 \mathrm{~cm}$ than when the distance was more than $30 \mathrm{~cm}(33.9 \%$ vs. $19.5 \%, \mathrm{P}=0.002)$. Additionally, the incidence of SBO was higher in patients who had undergone laparoscopic surgery than in those who had undergone open surgery ( $29 \%$ vs. $19.6 \%, \mathrm{P}=0.023)$ [5]. However, other studies did not show any significant difference in the incidence of postoperative SBO between the laparoscopic IPAA patients and the open IPAA patients [7, 8]. Marcello et al. [9] reported about obstruction after an IPAA. Among risk factors, including pouch type, steroid usage, prior obstruction, stomal rotation, and prior colectomy, only stomal rotation was a statistically significant high risk factor. Therefore, they concluded that stomal rotation was an unnecessary procedure and might be a cause of obstruction.

Kameyama et al. [10] reported on SBO after an IPAA with loop ileostomy in patients with UC. Twenty-two patients (22.9\%) had a SBO before ileostomy takedown. Among them, 11 patients required surgical intervention because of outlet obstruction (8 patients) and intra-abdominal adhesion (3 patients). However, one thing in study of Kameyama et al. [10] requires attention: the rate of patients who required surgery was high (50\%, 11 of 22 patients) compared to the rates reported in other papers. Fazio et al. [6] reported that 70 patients among 254 patients (27.6\%) with a SBO required surgery, and Mizushima et al. [5] reported that 28 patients among 111 patients (25.2\%) with a SBO required surgery. Moreover, although no information about the total number of outlet obstructions was provided, the rate of patients with an outlet obstruction who required surgical intervention was high (at least 36\%: at least 8 patients among 22 patients); Okita et al. [11] reported that 18 patients among 53 patients (33.9\%) with an outlet obstruction required surgery. In the abdominal computed tomography scan images [10], no significant differences in the stoma size at the skin and the fascia levels were observed between 
the $\mathrm{SBO}$ group and the non-SBO group (SBO group: $1.56 \mathrm{~cm}$ and $1.25 \mathrm{~cm}$; non-SBO group: $1.69 \mathrm{~cm}$ and $1.20 \mathrm{~cm}$, respectively). Although no significant differences were noted between the 2 groups, in the SBO group, the stoma size of $1.56 \mathrm{~cm}$ at the skin level and the stoma size of $1.25 \mathrm{~cm}$ at the fascia level seem small. Especially, the stoma size of $1.56 \mathrm{~cm}$ at the skin level in the SBO group tended to be smaller than the stoma size of $1.69 \mathrm{~cm}$ in the non-SBO group. Generally, when a loop ileostomy is created, the excised skin diameter is $2 \mathrm{~cm}, 2.5 \mathrm{~cm}$, or $3 \mathrm{~cm}$ or the final opening permits two fingers to pass easily $[2,5,12]$. Even when the shrinkage of the stoma over time is considered, the stoma sizes at the skin and the fascia levels in the SBO group seem small considering the sizes of the stomas cited above. I cautiously suspect that these small stoma sizes may have been the cause of the high rate of patients with outlet obstruction who required surgical intervention.

An IPAA with a loop ileostomy is the most commonly used surgical treatment for patients with UC. However, the complications that follow the procedure are factors that are associated with the overall outcome of the disease. As stated above, multiple risk factors contribute to the development of SBO; nevertheless, a thorough understanding of those risk factors should help prevent avoidable SBOs.

\section{CONFLICT OF INTEREST}

No potential conflict of interest relevant to this article was reported.

\section{REFERENCES}

1. Zhang Z, Kennedy H. Ulcerative colitis: current medical therapy and strategies for improving medication adherence. Eur J Gastroenterol Hepatol 2009;21:1-8.

2. Steele SR, Hull TL, Read TE, Saclarides TJ, Senagore AJ, Whitlow $\mathrm{CB}$, editors. The ASCRS textbook of colon and rectal surgery. 3rd ed. New York: Springer; 2016.
3. Kornbluth A, Sachar DB; Practice Parameters Committee of the American College of Gastroenterology. Ulcerative colitis practice guidelines in adults: American College Of Gastroenterology, Practice Parameters Committee. Am J Gastroenterol 2010;105: 501-23.

4. Ryoo SB, Oh HK, Han EC, Ha HK, Moon SH, Choe EK, et al. Complications after ileal pouch-anal anastomosis in Korean patients with ulcerative colitis. World J Gastroenterol 2014;20:748896.

5. Mizushima T, Kameyama H, Watanabe K, Kurachi K, Fukushima $\mathrm{K}, \mathrm{Nezu} \mathrm{R}$, et al. Risk factors of small bowel obstruction following total proctocolectomy and ileal pouch anal anastomosis with diverting loop-ileostomy for ulcerative colitis. Ann Gastroenterol Surg 2017;1:122-8.

6. Fazio VW, Ziv Y, Church JM, Oakley JR, Lavery IC, Milsom JW, et al. Ileal pouch-anal anastomoses complications and function in 1,005 patients. Ann Surg 1995;222:120-7.

7. Dolejs S, Kennedy G, Heise CP. Small bowel obstruction following restorative proctocolectomy: affected by a laparoscopic approach? J Surg Res 2011;170:202-8.

8. El-Gazzaz GS, Kiran RP, Remzi FH, Hull TL, Geisler DP. Outcomes for case-matched laparoscopically assisted versus open restorative proctocolectomy. Br J Surg 2009;96:522-6.

9. Marcello PW, Roberts PL, Schoetz DJ Jr, Coller JA, Murray JJ, Veidenheimer MC. Obstruction after ileal pouch-anal anastomosis: a preventable complication? Dis Colon Rectum 1993;36:110511.

10. Kameyama H, Hashimoto Y, Shimada Y, Yamada S, Yagi R, Tajima Y, et al. Small bowel obstruction after ileal pouch-anal anastomosis with a loop ileostomy in patients with ulcerative colitis. Ann Coloproctol 2018;34:94-100.

11. Okita Y, Araki T, Kondo S, Fujikawa H, Yoshiyama S, Hiro J, et al. Clinical characteristics of stoma-related obstruction after ileal pouch-anal anastomosis for ulcerative colitis. J Gastrointest Surg 2017;21:554-9.

12. Ellison EC, Zollinger RM Jr. Zollinger's atlas of surgical operations. 10th ed. New York: McGraw-Hill; 2016. 